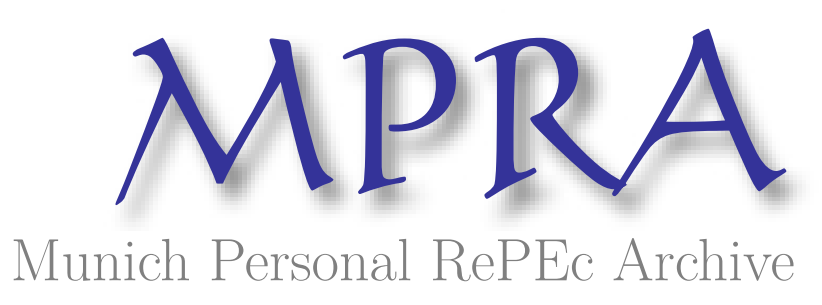

Sovereign Default and Capital Accumulation

Park, JungJae

December 2011

Online at https://mpra.ub.uni-muenchen.de/60150/

MPRA Paper No. 60150, posted 28 Nov 2014 15:57 UTC 


\title{
Sovereign Default and Capital Accumulation
}

\author{
JungJae Park*
}

First version: Dec. 2011

This version: Nov. 2014

\begin{abstract}
I introduce endogenous capital accumulation into an otherwise standard quantitative sovereign default model in the tradition of Eaton and Gersovitz (1981), and find that conditional on a level of debt, default incentives are U shaped in the capital stock: the economy with too small or too large amounts of capital is likely to default. In addition to an "excusable" motive for default in line with Grossman and Huyck (1989), our model also predicts an "opportunistic" motive for default in line with Kehoe and Levine (1993). The model predicts the "opportunistic" motive for default, because (1) capital is used as a consumption insurance vehicle during autarky after default, (2) installed capital within the border cannot be seized by foreign lenders, and (3) our model does not use an ad-hoc output cost of default which only penalizes default in high income states. The two different motives for default allow the calibrated model to generate defaults in "good" and "bad" times in simulation with a frequency of $38 \%$ and $62 \%$, respectively. This is consistent with Tomz and Wright (2007)'s empirical finding that throughout history and across countries, around one third of sovereign defaults occurred in "good" times, when output is above trend, whereas most defaults occur in "bad" times. The model is calibrated to the business cycle moments of Argentina, and simulation results show that the model matches business cycle facts regarding emerging economies along other dimensions. Moreover, simulation results show that default in "good" times occurs (1) after the economy has accumulated a significantly large amount of capital and (2) when the economy faces a modestly good shock, both of which reduce the value of external borrowing but increase the value of staying in autarky. On the other hand, around defaults in "bad" times, the model economy displays typical "V" shape economic dynamics, with a collapse in absorption upon default, especially investment. Aggregating quarterly data from the model into annual frequency is found to overestimate the fraction of defaults in "good" times around twofold. (JEL: E32, E44, F32, F34)
\end{abstract}

${ }^{*}$ Department of Economics, National University of Singapore, 1 Arts Link Singapore 117570, Singapore. Email: ecspj@nus.edu.sg. Homepage: https://sites.google.com/site/suhyoondad/home. I am extremely grateful to Charles Engel for his advice and encouragement. I also thank Dean Corbae, Kenneth West, Larry Christinano, Kennich Fukushima, Federico Mandelman, and audiences in the seminars at Atlanta Fed, UW-Madison, and NUS for helpful comments. The project benefited from discussion with YeJin Chung, Kyu-Chul Jung, and SangYoon (Tim) Lee. Part of this paper was being written while I was visiting the Federal Reserve Bank of Atlanta as a dissertation intern in the summer of 2011. I am grateful for their hospitality during my stay at the Bank, especially to Stephen Kay and Vanessa Jordan. All errors are mine. 
Figure 1: Ecuador's Economic Activity and Defaults

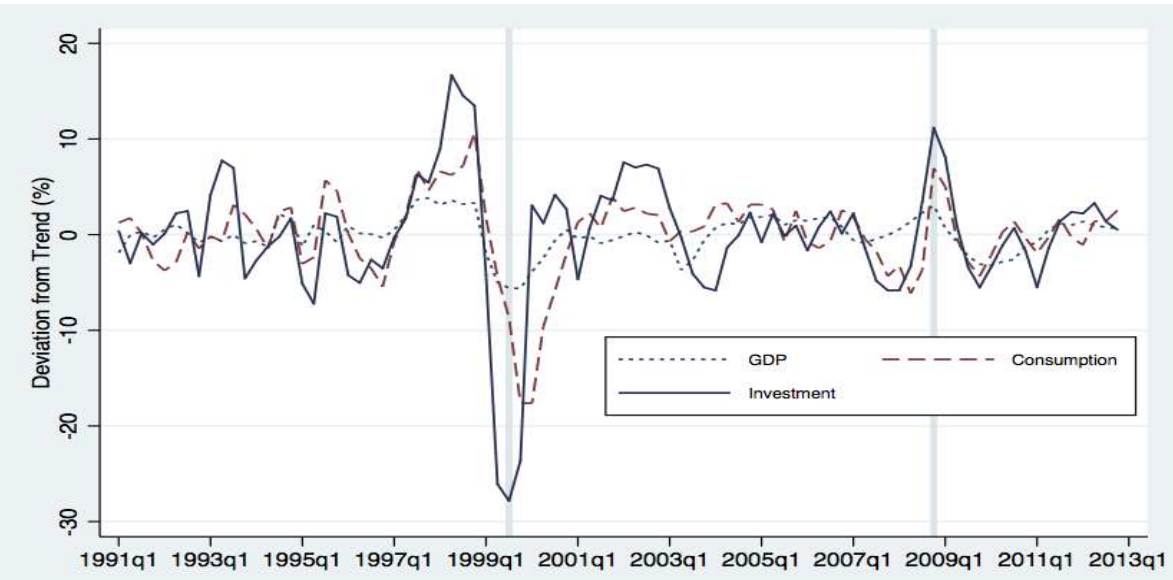

Note: Data runs from 1991Q1 through 2012Q4. Data source: IFS. All series are seasonally adjusted and HP filtered with a smoothing parameter of 1600 .

\section{Introduction}

Do countries default only in "bad times"? No. In December of 2008, Ecuador defaulted on its external debt when the country failed to pay a $\$ 30.6$ million interest payment on its external debt. What is interesting about Ecuador's default in 2008 is that at the time of default, Ecuador had around 6 billion dollars in foreign reserve and its external debt amounted to $\$ 10.2$ billion, which accounted for only around $25 \%$ of its GDP. Moreover, the annual growth rate of GDP in 2008 was 6.5\%. This suggests that Ecuador defaulted on its external debt in "good times", not to mention that it had more than sufficient resources to honor its debt with. On the contrary to Argentina's default in 2002, which occurred after a long period of economic downturn and thus was considered as "excusable", Ecuador's default can be considered as "inexcusable" or "opportunistic".

Figure 1 shows time-series plots of GDP, consumption, and investment for Ecuador, all detrended through the HP filter with a smoothing parameter of 1600 for the period 1991Q1 through 2012Q4. The Ecuador government defaulted on its external debt twice over the last two decades: August of 1999 and December of 2008. Around the default in 1999, we see typical economic dynamics associated with sovereign defaults in "bad" times: at the time of default, output, consumption, and investment were 5.6\%, 8.7\%, and $27.8 \%$ below trend, respectively. Up until the two quarters after default, all the relevant variables have stayed much below the trend, and since then these variables start to revert back to the trend. This is wellknown "V" shape macroeconomic dynamics of sovereign debt crises for emerging economies documented by Mendoza and Yue (2012). In contrast, at the time of 2008's default, Ecuador displayed inverted "V" shape dynamics: at the time of default, output, consumption, and investment were $3 \%, 6.9 \%$, and $11.1 \%$ above trend, respectively, and subsequently output, consumption, and investment have started to decrease, but to a much less degree, than in 1999's default.

Sovereign default in "good times" is, however, neither new nor unique to Ecuador. Tomz and Wright (2007) studies the relationship between sovereign default and output for the period 1820-2004 and across 
countries and finds that around one third of sovereign defaults occurred in "good times", when output is above trend. Durdu et al. (2013) also documents episodes of defaults in good times with a new data set, supplementing Tomz and Wright (2007). Tomz and Wright (2007) claims that this finding is puzzling, because sovereign default models in the tradition of Eaton and Gersovitz (1981) fail to generate default in good times.

Sovereign default in bad times is in line with "excusable" default, a notion proposed by Grossman and Huyck (1989) that defaultable sovereign debt can be viewed as contingent claims that convey partial consumption insurance to countries in bad income states. The default in bad times is the main prediction of sovereign default models in the tradition of Eaton and Gersovitz (1981); except for few studies, this is the only prediction. On the contrary, sovereign default in good times is in line with the optimal contract models in the presence of limited commitment such as the studies by Kehoe and Levine (1993) and Kocherlakota (1996), in that the models of these studies predict high default incentives in high income states, even if default does not occur in equilibrium.

This paper introduces capital accumulation into an otherwise standard quantitative sovereign default model in the tradition of Eaton and Gersovitz (1981) and finds that conditional on a level of debt, default incentives display a "U" shape in the capital stock as in Figure 3: default incentives are high at a low level of capital, but decrease as the capital stock increases. Above a certain level of capital, however, default incentives are reversed to increase in the capital stock. Finally, when the economy has a sufficiently large stock of capital, the default incentives gets so high that the economy decides to default. That is, by introducing capital accumulation, our model predicts the two different motives for default, thus bridging the gap between the two main strands of sovereign default models. This is one of the novel findings of our paper. Moreover, simulation results show that in addition to defaults in bad times, our model generates defaults in good times with a significantly high frequency of $37.9 \%$, which is very close to the estimate of Tomz and Wright (2007) of 38.5\%. Thus, our model can account for the puzzling empirical findings simply by introducing capital accumulation.

The setup of our model is similar to Aguiar and Gopinath (2006) and Arellano (2008) except that the model economy features a production technology and capital accumulation. Sovereign debt is not enforceable, and at any time a benevolent sovereign government decides to default after comparing the values of default and repayment. A small open economy produces capital using a CES Armington aggregator that combines domestic and foreign inputs. This assumption is in line with several empirical studies such as Eaton and Kortum (2001) and Burstein et al. (2004), which find that in producing capital goods, emerging economies rely heavily on foreign investment goods imported from advanced economies. Default is punished by temporary autarky, during which the economy is banned from saving/borrowing in international financial markets and importing foreign inputs in world markets. Hence, there are two types of punishment for default: during autarky, the economy loses a savings instrument, and it is more costly to accumulate capital because domestic and foreign inputs are imperfect substitutes in producing capital. Mendoza and Yue (2012) also uses the similar CES aggregator and assumptions about domestic and foreign inputs, which lead to inefficiency in production during autarky after default.

Like most sovereign default models in the tradition of Eaton and Gersovitz (1981), our model predicts the excusable motive for default: high default incentives in low income states. In low income states, the economy's debt relative to income is high, and this coincides with the case of a high marginal utility of 
consumption. For the case of the high marginal utility of consumption, the gain of the increase in current consumption from default exceeds the cost of default, thus leading to the economy's default. In this case, default conveys consumption insurance to the economy in low income states.

In addition to the motive for excusable default, our model also predicts a motive for opportunistic default: the economy with a sufficiently large amount of capital is likely to default. There are three main reasons for this prediction. First, capital can be used as a consumption-insurance vehicle during autarky in the similar spirit of Aiyagari (1994). The economy with large amounts of capital can maintain its consumption even during autarky; hence the cost of default is not high and the value of borrowing from foreign lenders is not high, either. Second, installed capital within the border cannot be seized by foreign lenders due to sovereignty of the country. Third, our model does not use the ad-hoc output cost of default, commonly used by quantitative sovereign default models, which only penalizes default which occurs in good times.

It must be noted that the models in the line of Eaton and Gersovitz (1981) feature the non-contingent bond only framework, whereas the models in the line of Kehoe and Levine (1993); Kocherlakota (1996) feature the framework with fully state contingent securities. Introducing capital accumulation makes the defaultable debt in our model more state contingent, bringing it closer to the framework in the line of Kehoe and Levine (1993); capital is another state variable affecting default decisions in our model.

The model is numerically solved and calibrated to match the business cycle statistics of Argentina. Simulation results show that the model generally accounts for other business cycle facts unique to emerging economies. The event study shows that defaults in "good" times occur (1) after the economy has accumulated a significantly large amount of capital stock and (2) when the economy faces a modestly good shock, both of which reduce the value of external borrowing but increase the value of staying in autarky. Moreover, the model economy around the defaults in good times, on average, displays inverted "V" macroeconomic dynamics qualitatively similar to the Ecuador's 2008 default. On the other hand, the model economy around the defaults in "bad" times displays typical "V" shape economic dynamics accompanied with a collapse in absorption upon default, especially investment. Finally, I find that aggregating quarterly data from the model into annual frequency overestimates the fraction of defaults in "good" times around twofold. This suggests that the empirical finding by Tomz and Wright (2007) and Durdu et al. (2013) must be interpreted more carefully.

This paper relates to recent quantitative sovereign default models in the tradition of Eaton and Gersovitz (1981). ${ }^{1}$ The setup of the model is similar to Mendoza and Yue (2012) which features a production technology with the CES aggregator, but their model abstracts from capital accumulation. Gordon and Guerron-Quintana (2013), and Roldan (2012) also introduce capital accumulation into an otherwise standard sovereign default model, but assume a typical cost of default which is increasing in output, so that their models only predict that default incentives are decreasing in the capital stock. Hatchondo et al. (2009) introduces political uncertainty, so that the model predicts a loose relationship between default and output; in their model, default incentives also depend on political factors unrelated to economic fundamentals. Durdu et al. (2013) introduces news shocks so that their model also succeeds in generating defaults in good times in simulation, but with a much less frequency than our model. Hence, this paper complements their study. However, our model can generate the high fraction of defaults in good times

\footnotetext{
${ }^{1}$ A short list includes Aguiar and Gopinath (2006), Arellano (2008), Yue (2010), and Mendoza and Yue (2012).
} 
without resorting to any information friction.

The rest of the paper is organized as follows. Section 2 describes the model environment and defines the recursive equilibrium of the economy. Section 3 presents main quantitative results of the model, and Section 4 concludes.

\section{The Model Economy}

We consider a small open economy model in which there are a representative household and a sovereign government in a small country, and foreign lenders in international financial markets. The setup of the model is close to Aguiar and Gopinath (2006) and Arellano (2008), except that our model features capital accumulation as well as a production technology. As typical of quantitative sovereign default models in the tradition of Eaton and Gersovitz (1981), the benevolent government decides on how much to borrow/save from foreign lenders and makes a default decision on its external debt to maximize the household's welfare. Moreover, the government makes an investment decision for the economy's capital accumulation, which involves importing foreign investment goods. Upon default, the economy is thrown into autarky for a random period of time, during which the economy loses access to international financial markets and foreign investment goods markets. Once the economy gets out of autarky, it starts anew with zero debt, resuming borrowing/savings with foreign lenders and importing foreign investment goods.

\subsection{Household}

The representative household in a small open economy chooses consumption and labor supply so as to maximize the following time separable utility function:

$$
E_{o} \sum_{t=0}^{\infty} \beta^{t} u\left(c_{t}-G\left(l_{t}\right)\right),
$$

where $\beta$ denotes the time discount factor, $c_{t}$ consumption, and $l_{t}$ labor input in period t. $u(\cdot)$ is strictly increasing and strictly concave and satisfies the standard Inada conditions. $G(\cdot)$ measures disutility of labor and is convex and strictly increasing in $l_{t}$. Hence, the period utility is a function of consumption net of disutility of labor. This utility function was first introduced by Greenwood et al. (1988) (GHH) and features no wealth effect on labor supply. The GHH utility function is widely used in small open economy models and known to be effective at matching business cycles of emerging economies.

The household owns a production technology and produces a tradable consumption good using two inputs: capital and labor. The production function is Cobb-Douglas:

$$
y_{t}=\exp \left(A_{t}\right) K_{t}^{\alpha} l_{t}^{1-\alpha}
$$

where $A_{t}$ denotes a TFP shock, $K_{t}$ capital, and $l_{t}$ labor in period $t . \alpha$ is the capital share of output. $A_{t}$ follows an $\mathrm{AR}(1)$ process:

$$
A_{t}=(1-\rho) \bar{\mu}+\rho A_{t-1}+\epsilon_{t},
$$

where $|\rho|<1, \epsilon_{t} \sim N\left(0, \sigma_{\epsilon}^{2}\right)$. 
The household faces the following budget constraint:

$$
c_{t}=y_{t}+T_{t}
$$

where $T_{t}$ denotes a lump-sum transfer from the government. The representative household does not engage in any credit operation abroad, but the government does with foreign lenders in international financial markets as typical in the quantitative sovereign default models. The optimality condition for the labor supplied by households is given by :

$$
G^{\prime}\left(l_{t}\right)=(1-\alpha) \exp \left(A_{t}\right) K_{t}^{\alpha} l_{t}^{-\alpha}
$$

\subsection{Capital Accumulation}

The law of motion for capital is given by:

$$
K_{t+1}=(1-\delta) K_{t}+I_{t}\left(i_{t}^{d}, i_{t}^{f}\right)
$$

where $I_{t}$ is gross investment in period $t$ and is produced using a CES Armington aggregator that combines a domestic investment good (input) $i_{t}^{d}$ and a foreign investment good (input) $i_{f}^{f}$. The domestic investment good $i_{t}^{d}$ can be transformed one for one from the consumption good $y_{t}$ without any costs, whereas the

foreign input $i_{t}^{f}$ must be imported from abroad at a constant price $p_{f}$ in units of the consumption good (numeraire). The Armington aggregator for the investment is given by:

$$
I_{t}\left(i_{t}^{d}, i_{t}^{f}\right)=\left[\lambda\left(i_{t}^{d}\right)^{\varepsilon}+(1-\lambda)\left(i_{t}^{f}\right)^{\varepsilon}\right]^{\frac{1}{\varepsilon}}
$$

where it is assumed that $0<\lambda<1$ and $\varepsilon<1$, so that Armington elasticity of substitution between domestic and foreign investment goods is $\left|\frac{1}{\varepsilon-1}\right|$. Hence, domestic and foreign investment goods are imperfect substitutes. The imperfect substitutability between $i^{d}$ and $i^{f}$ in producing capital is related to a cost of default in our model: during autarky after default, the country is banned from importing the foreign investment input, so it is costly for the economy to accumulate capital with its own investment good $i^{d}$ alone. The CES specification of aggregating domestic and foreign inputs is similar to that used in Mendoza and Yue (2012) and Gopinath and Neiman (2014), but both studies use the CES aggregator to produce intermediate goods, not capital as in our model.

It is appropriate to emerging economies to assume that producing capital goods requires a mix of domestic and foreign inputs, rather than domestic inputs only. Eaton and Kortum (2001) finds that only a small number of advanced countries are the major exporters of capital goods to the rest of the world, implying that developing countries depend heavily on foreign investment goods in producing and accumulating capital. Using input-output table data from nineteen countries, Burstein et al. (2004) also finds that the import content of investment is significant for many developing countries including Argentina, to which our model is calibrated. Moreover, using the data for the developing countries for the period 1980-1997, Alfaro and Hammel (2007) finds that developing countries who open up their market to world markets enjoyed the economic benefits of getting transferred of technology from importing capital goods which embody advanced technology of advanced countries. 
The cost-minimization problem for producing one unit of investment $I$ is given by

$$
\min _{i_{t}^{d}, i_{t}^{f}} i_{t}^{d}+p_{f} i_{t}^{f}
$$

subject to

$$
\left[\lambda\left(i_{t}^{d}\right)^{\varepsilon}+(1-\lambda)\left(i_{t}^{f}\right)^{\varepsilon}\right]^{\frac{1}{\varepsilon}}=1
$$

An interior solution to the cost-minimization problem gives us an optimal mix of $i_{t}^{d *}$ and $i_{t}^{f *}$ for producing one unit of investment $I_{t}$ :

$$
\begin{gathered}
i_{t}^{d *}=\lambda^{\frac{1}{1-\epsilon}}\left(\lambda^{\frac{1}{1-\epsilon}}+p_{f}^{\frac{\epsilon}{\epsilon-1}}(1-\lambda)^{\frac{1}{1-\epsilon}}\right)^{-\frac{1}{\epsilon}} \\
i_{t}^{f *}=p_{f}^{\frac{1}{\epsilon-1}}(1-\lambda)^{\frac{1}{1-\epsilon}}\left(\lambda^{\frac{1}{1-\epsilon}}+p_{f}^{\frac{\epsilon}{\epsilon-1}}(1-\lambda)^{\frac{1}{1-\epsilon}}\right)^{-\frac{1}{\epsilon}}
\end{gathered}
$$

The cost of producing one unit of investment in terms of the consumption goods is as follows:

$$
\begin{gathered}
p_{k}=\left[\lambda^{\frac{1}{1-\epsilon}}+p_{f}^{\frac{\epsilon}{\epsilon-1}}(1-\lambda)^{\frac{1}{1-\epsilon}}\right]^{\frac{\epsilon-1}{\epsilon}} \\
p_{k+}^{\text {aut }}=\lambda^{-\frac{1}{\epsilon}}
\end{gathered}
$$

where $p_{k}$ and $p_{k+}^{a u t}$ is the cost of producing one unit of investment during normal times and during autarky, respectively. For the interior solution, we have $p_{k+}^{a u t}>p_{k}$. That is, it is more costly to accumulate capital during autarky.

The installed capital stocks within the border of the country cannot be seized by foreign creditors due to sovereignty of the country, even when the government defaults on its external debt. This characteristic of capital gives potential for our model to predicts an opportunistic motive for default as we will discuss in section 3.2 .

\subsection{Sovereign Government}

The government in the small open economy is benevolent, so that its objective is to maximize the utility of the household. The government trades one period non-contingent discount bonds with foreign lenders in international financial markets, but it cannot commit to repay its debt due to lack of enforcement in sovereign debt. The government decides whether to default on its external debt or not, after comparing values of default and repaying. The government also makes an investment decision for the economy. From now on, I follow a convention that superscript' (prime) denotes a variable at the next period.

\section{Value of Option to Default}

There are three state variables characterizing the current state of the small open economy: current foreign bond holdings $B^{2}$, capital $K$, and a total factor productivity (TFP) shock $A$. Let $V^{o}(B, K, A)$ be the value function for the government with an option to default, conditional that the economy is not in autarky. $V^{o}(B, K, A)$ is then given by :

\footnotetext{
${ }^{2} \mathrm{~B}>0$ means that the economy holds a positive amount of foreign financial assets, whereas $\mathrm{B}<0$ means that the economy is in debt.
} 


$$
V^{o}(B, K, A)=\max \left(V^{n d}(B, K, A), V^{d}(K, A)\right),
$$

where $V^{n d}$ denotes the value of repayment, the value function of the government not defaulting and honoring the debt with foreign lenders, and $V^{d}$ the value of default. If the value of default $V^{d}$ exceeds the value of no-default $V^{n d}$, the sovereign government chooses to default on its external debt. Otherwise, the government rolls over its current bond holdings (debt) $B$ with a new borrowing $B^{\prime}$ from foreign lenders.

\section{Value of Repayment}

When the government decides to pay back its external debt $B$ (i.e., not default), the government chooses $B^{\prime}$ and $K^{\prime}$, and then makes a transfer $T$ to households in a lump sum fashion.

The value of repayment is then given by

$$
V^{n d}(B, K, A)=\max _{c, l, B^{\prime}, i_{d}, i_{f}, K^{\prime}} u(c, l)+\beta E\left[V^{o}\left(B^{\prime}, K^{\prime}, A^{\prime}\right) \mid A\right],
$$

subject to the following constraints:

$$
\begin{gathered}
c+p_{k} I+q\left(B^{\prime}, K^{\prime}, A\right) B^{\prime}+\Phi\left(K, K^{\prime}\right)=\exp (A) f(K, l)+B \\
K^{\prime}=(1-\delta) K+I \\
I=\left[\lambda\left(i_{d}\right)^{\varepsilon}+(1-\lambda)\left(i_{f}\right)^{\varepsilon}\right]^{\frac{1}{\varepsilon}} \text { for } \quad I>0 \\
i_{d} \geq 0, i_{f} \geq 0 \\
p_{k}=\left[\lambda^{\frac{1}{1-\epsilon}}+p_{f}^{\frac{\epsilon}{\epsilon-1}}(1-\lambda)^{\frac{1}{1-\epsilon}}\right]^{\frac{\epsilon-1}{\epsilon}},
\end{gathered}
$$

where $\Phi\left(K, K^{\prime}\right)$ is a capital adjustment cost function, which is typically used in small open economy models and is used to prevent too much volatility of investment of the small open economy. When the government chooses $B^{\prime}$ and capital $K^{\prime}$, it takes the bond price schedule $q\left(B^{\prime}, K^{\prime}, A\right)$ as given. The government, however, internalizes the effect of its choice of $B^{\prime}$ and $K^{\prime}$ on bond price schedule $q\left(B^{\prime}, K^{\prime}, A\right)$, which reflects the probability of default for the next period. The government also faces a lower bound on debt, $B^{\prime} \geq-Z$, which prevents the Ponzi scheme.

\section{Value of Default}

When the government defaults on its debt, the country enters autarky for a random period of time, during which it loses access to both international financial markets and foreign investment goods markets.

The value of default is given by:

$$
V^{d}(K, A)=\max _{c, l, i^{d}, K^{\prime}} u(c, l)+\theta \beta E\left[V^{o}\left(0, K^{\prime}, A^{\prime}\right) \mid A\right]+(1-\theta) \beta E\left[V^{d}\left(K^{\prime}, A^{\prime}\right) \mid A\right]
$$

subject to

$$
\begin{gathered}
c+p_{k}^{a u t}\left(K, K^{\prime}\right) I+\Phi\left(K, K^{\prime}\right)=\exp (A) f(K, l) \\
K^{\prime}=(1-\delta) K+I
\end{gathered}
$$




$$
\begin{gathered}
p_{k}^{\text {aut }}\left(K, K^{\prime}\right)=\left(p_{k+}^{\text {aut }} \mathbf{1}\left[K^{\prime}>(1-\delta) K\right]+p_{k-}^{\text {aut }} \mathbf{1}\left[K^{\prime} \leq(1-\delta) K\right]\right) \\
I=\lambda^{\frac{1}{\epsilon}} i_{d} \quad \text { for } \quad I>0 \\
p_{k+}^{\text {aut }}=\lambda^{-\frac{1}{\varepsilon}} \quad \text { for } \quad I>0 \\
p_{k-}^{\text {aut }} \equiv p_{k} \text { for } \quad I \leq 0,
\end{gathered}
$$

where $\mathbf{1}[$.$] is an indicator function which takes on the value of one if investment is positive and the$ value of zero, otherwise. $p_{k+}^{a u t}$ is the price of a newly produced capital good during autarky, which is given by $\lambda^{-\frac{1}{\epsilon}}$ from the eq (12), whereas $p_{k-}^{a u t}$ is the liquidation value of capital during autarky and it is set equal to $p_{k}$, the price of capital during normal times. Note that if the liquidation value of capital during autarky is set equal to $p_{k+}^{a u t}$, which is larger than $p_{k}$, then the value of the capital stock suddenly gets higher upon default, which is counterfactual.

During autarky, the economy must consume only what is produced within its borders and accumulate capital using the domestic investment good only (eq 25), because it is excluded from both international financial markets and foreign investment goods markets. In the subsequent periods after default, there is, however, a chance of regaining access to both markets with an exogenous probability $\theta$. Moreover, when the economy gets out of autarky, the economy starts off with zero debt, which can be seen from the first argument of $V^{o}$ being zero in equation (21).

\section{Cost of Default}

There are two types of punishment for default in this model: reputation and trade sanction, consistent with the two main punishments broadly categorized by the sovereign debt literature. The former relates to the assumption that during autarky after default, the country loses access to international financial market for a certain period of time. This implies that a defaulting country loses an instrument for consumption smoothing through borrowing/savings in international financial markets. This assumption is shared among quantitative sovereign default models. However, as Lucas (1987) points out, the value of financial instruments which insure an economy against idiosyncratic income shocks is not high, so that the cost of default associated with this type of punishment would not be quantitatively high in our model. Without further punishment for the default, the model economy would then default too often in equilibrium, even at a very low level of indebtedness.

As a second punishment for default, the defaulting country is assumed to be banned from importing foreign investment goods during autarky due to the trade sanction imposed upon the defaulting country. Since domestic and foreign inputs are imperfect substitutes, this leads to inefficiency in producing capital for the defaulting country. The trade sanction as a punishment for default is supported by a number of empirical studies regarding sovereign default. Kalesky (1985) finds in his study on defaulting countries in the 1980s that the most severe penalty for defaulters comes from trade sanction imposed by lenders, which greatly disrupted defaulting countries' manufacturing sectors. Using the sample consisting of a total of 116 defaults in the last 30 years, Martinez and Sandleris (2011) finds that sovereign defaults are associated with a decline in overall trade for the defaulting country. Mendoza and Yue (2012) also makes a similar 
trade-sanction assumption for the defaulting country, but in their model, the country is assumed to be banned from importing a subset of foreign inputs used to make an intermediate good.

With few exceptions including this paper, quantitative sovereign default models in the tradition of Eaton and Gersovitz (1981), whether featuring an endowment economy or a production economy, assume an ad-hoc cost of default which is increasing in income of the country. For example, Arellano (2008) assumes that there is no cost of default in the form of income loss, when the country's income is below its mean, but that the default cost is strictly increasing in income for the levels above the mean. As a result, in equilibrium, these models predict high default incentives in low income times (bad times), thus generating default only in bad times as shown by Tomz and Wright (2007). On the other hand, the specification of default cost in our model does not necessarily dictate the model to predict high default incentives in bad times: the model also predict high default incentives in high income times. (i.e., opportunistic default). This point will be discussed in detail in section 3.6.

\subsection{Foreign Creditors in International Financial Markets}

Foreign creditors in international financial markets have perfect information about the economy. They are risk-neutral and competitive so that they price one period bonds such that they have expected zero profits. Given the economy's default probability of $\mu$ for the next period, the expected zero profit condition requires the following bond prices:

$$
q=\frac{1-\mu}{1+r_{f}}
$$

where $r_{f}$ is the prevailing world risk-free rate, which is constant across time and states and is taken as given by the small open economy.

The economy's default probability $\mu$ is endogenous to the model and depends on the government's default incentives. Note that for a positive amount of bond holdings $B^{\prime}>0$, the default probability $\mu$ is zero, because there is no incentive for the government to default. Therefore, the bond price $q$ is the inverse

of the gross risk-free rate $\frac{1}{1+r_{f}}$ for positive bond holdings. On the other hand, for positive values of $\mu$, the bond price $q$ is less than $\frac{1}{1+r_{f}}$.

\section{Default Set and Bond Price Schedule}

Following Arellano (2008), default sets and bond price schedules are defined as follows. Let $D(B, K)$ be a default set, which is a set of TFP shocks for which the government optimally chooses to default, given its bond holdings $B$ and capital $K$.

$$
D(B, K)=\left\{A \in \mathcal{A}: V^{D}(A, K) \geq V^{N D}(B, A, K)\right\}
$$

Then default probabilities $\mu\left(B^{\prime}, K^{\prime}, A\right)$ for the next period are determined in the following way.

$$
\mu\left(B^{\prime}, K^{\prime}, A\right)=\int_{A^{\prime} \in D\left(B^{\prime}, K^{\prime}\right)} f\left(A^{\prime} \mid A\right) d A^{\prime}
$$

The default probabilities also depend on the current TFP shock $A$ because of persistence of the TFP shock process. With the next period's default probability of $\mu\left(B^{\prime}, K^{\prime}, A\right)$, we have the bond price schedules 
given by

$$
q\left(B^{\prime}, K^{\prime}, A\right)=\frac{1-\mu\left(B^{\prime}, K^{\prime}, A\right)}{1+r_{f}}
$$

\subsection{Recursive Equilibrium}

The equilibrium concept in this economy is a recursive Markov perfect equilibrium to prevent a timeinconsistency problem of the government's default decision. Let $s=\{x, d\}$ be a set of state variables for the economy, where $x=(B, A, K)$, and $d=1$ indicates autarky periods and $d=0$ no-autarky periods.

Definition 1: A recursive equilibrium for this economy is defined as a set of policy functions for consumption $C(s)$, labor $L(s)$, default decision $D(s)$, bond holdings for the next period $B^{\prime}(s)$ and capital for the next period $K^{\prime}(s)$, a bond price schedule $q(s)$, and value functions for the government $\left\{V^{o}(s), V^{d}(s), V^{n d}(s)\right\}$ satisfying the following equilibrium conditions.

1. Given the bond price schedule $q(s)$, the policy functions and the value functions solve the government's optimization problem.

2. Bond price schedule $q(s)$ depends on default probabilities given by eq (30) and is consistent with the zero profit condition for the foreign lenders in international financial markets (eq (28)).

3. The optimality condition for labor supply is given by eq (5).

4. The optimal mix of domestic and foreign inputs for producing capital is given by eq $(10,11)$. 
Table 1: Parameters

\begin{tabular}{|c|c|c|c|}
\hline From Literature & & & \\
\hline$\gamma$ & 2 & Risk aversion parameter & Literature \\
\hline$r_{f}$ & $1 \%$ & Risk free rate & Literature \\
\hline$\omega$ & 1.453 & Curvature parameter of labor supply & Mendoza (1991) \\
\hline$\alpha$ & 0.35 & Capital income share & Literature \\
\hline$\delta$ & 0.025 & Depreciation rate & Literature \\
\hline$\rho_{\epsilon}$ & 0.95 & Degree of persistence in stochastic shocks & Aguiar and Gopinath (2007) \\
\hline$\theta$ & 0.25 & Expected autarky period is 1 year. & Gelos et al. (2011) \\
\hline$\lambda$ & 0.62 & Armington Weight of Domestic Investment goods & Mendoza and Yue (2012) \\
\hline$\epsilon$ & 0.65 & Armington Curvature Parameter & Mendoza and Yue (2012) \\
\hline \multicolumn{4}{|c|}{ Using Argentina's data } \\
\hline$p_{f}$ & 0.34 & Price of the foreign input & Penn World Table \\
\hline From Simulation & & & Target Statistics \\
\hline$\beta$ & 0.86 & Time discount factor & Rate of Default (2.76 per 100 years) \\
\hline$\sigma_{\epsilon}$ & 0.019 & Standard deviation of stochastic shocks & Volatility of output $\left(\sigma_{y}\right)$ \\
\hline$\kappa$ & 21.0 & Capital adjustment cost & Investment volatility $\left(\sigma_{I}\right)$ \\
\hline
\end{tabular}

\section{Quantitative Analysis}

\subsection{Calibration and Functional Forms}

The model is solved numerically and simulated to investigate quantitative implications of capital accumulation for default incentives and macroeconomic dynamics around default. The model is calibrated to match business cycle statistics of Argentina, which is a standard practice in quantitative studies of sovereign default. A period in the model is a quarter. The following utility function (GHH) is used for the numerical simulations:

$$
U\left(c_{t}, l_{t}\right)=\frac{\left[c_{t}-\frac{l_{t}^{\omega}}{\omega}\right]^{1-\gamma}-1}{1-\gamma}
$$

Table 1 lists baseline parameters. The risk aversion coefficient $\gamma$ is set to be 2 , which is a standard value in the literature. The parameter that determines the labor supply elasticity of wage in the GHH utility function, $\omega$ is set equal to 1.455. This value is also employed in Mendoza (1991) and Neumeyer and Perri (2005) among others. The quarterly risk free rate is set at 1\%. The persistence of TFP shocks $\rho_{\epsilon}$ is set equal to 0.95 and is from Aguiar and Gopinath (2007), which estimates the stochastic process of TFP shocks using Argentina's data. Capital's share of income $\alpha$ and a quarterly capital depreciation rate $\delta$ are set to be 0.35 and 0.025 , respectively. The probability of the small economy getting out of autarky $\theta$ is 
set to be 0.25 , implying that the expected autarky period after default is one year. This is in the range of the estimates of Gelos et al. (2011).

The Armington weight of the domestic investment good $\lambda$ and the Armington curvarture parameter $\epsilon$ are set to be 0.62 and 0.65 , respectively. These values are adopted from Mendoza and Yue (2012), which estimates both parameters using Mexico data, even though in their model, domestic and foreign inputs are mixed to produce an intermediate good. The price of the foreign input $p_{f}$ relative to the consumption good is chosen so that the relative price of the capital good $p_{k}$ to the consumption good is 0.92 during normal times, an estimate for Argentina using data from Penn World Table (Version 8.0) for the period 1996-2000. The price of the capital good $p_{k}$ of 0.92 is also in the range of estimates by Lee (1995), which investigates the relative price of capital to consumption goods across countries during the 1980s. With the calibrated values of $\lambda$ and $\epsilon$, the autarky price of new capital $p_{k+}^{a u t}$ is 2.16 . That is, it is more than twice costly to accumulate capital during autarky.

The following standard quadratic capital adjustment cost function is used:

$$
\Phi\left(K_{t}, K_{t+1}\right)=\frac{\kappa}{2}\left(\frac{K_{t+1}-(1-\delta) K_{t}}{K_{t}}\right)^{2} K_{t},
$$

where subscript denotes a time period.

The time discount factor $\beta$, the standard deviation of TFP shocks $\sigma_{\epsilon}$, and the capital adjustment cost parameter $\kappa$ are jointly calibrated so as to match the following three moments in Argentina's data: the default rate of Argentina for 100 years of 2.76, the standard deviation of output $\left(\sigma_{y}\right)$ of $4.08 \%$, and the ratio of $\sigma(I) / \sigma(Y)$ of 2.95 .

The calibrated time discount factor $\beta$ is 0.86 , much lower than that of standard RBC models. Low values of $\beta$ are, however, typical in quantitative models of sovereign default ${ }^{3}$ and are necessary to generate a reasonable rate of default in equilibrium. The capital adjustment cost parameter $\kappa$ is calibrated to be 21 , which is in the range of values (12-25) used in Neumeyer and Perri (2005), which also matches the ratio of the volatility of investment to that of output for Argentina in calibration.

To approximate a continuous AR(1) process for the TFP shocks, I use a Markov approximation with 31 equally spaced grids using the discretization method proposed by Tauchen (1986). I discretize bond and capital spaces into 200 and 700 equally spaced grid points, respectively. Hence, the state space of the model has $200^{*} 700^{*} 31$ coordinates. Adding one more endogenous state variable (capital) makes the model significantly harder to solve numerically, so parallel computing with 12 CPUs is used.

In solving for the equilibrium of the model, both value and bond price functions are iterated until convergence. It was ensured that the policy functions for bond holdings and capital $\left(B^{\prime}\right.$ and $\left.K^{\prime}\right)$ do not hit the upper/lower bounds of respective variable. The detailed computational algorithm is in the Appendix 1.

\section{$3.2 \quad$ Results}

\section{Business Cycle Statistics of the Model}

Table 2 compares key business cycle statistics from the baseline model economy (column (II)) and the data (column (I)) for Argentina for the period 1983Q1-2001Q4 (one quarter before Argentina's default).

\footnotetext{
${ }^{3}$ The value of $\beta$ in the quantitative sovereign default literature ranges from 0.8 to 0.95 .
} 
Table 2: Business Cycle Statistics

\begin{tabular}{|c|c|c|}
\hline & $\begin{array}{c}(\mathrm{I}) \\
\text { Data }\end{array}$ & $\begin{array}{c}\text { (II) } \\
\text { Baseline Model }\end{array}$ \\
\hline \hline$\sigma(y)$ & 4.22 & 4.27 \\
\hline$\sigma(c) / \sigma(y)$ & 1.17 & 0.95 \\
\hline$\sigma(I) / \sigma(y)$ & 2.95 & 2.90 \\
\hline$\sigma\left(\frac{T B}{y}\right)$ & 1.42 & 0.40 \\
\hline$\sigma\left(R_{s}\right)$ & 3.87 & 1.60 \\
\hline$\rho(T B / Y, Y)$ & -0.89 & -0.33 \\
\hline$\rho\left(R_{s}, Y\right)$ & -0.63 & -0.25 \\
\hline Fraction of defaults in "good" times & $38.5 \%^{a}$ & $37.9 \%^{b}$ \\
\hline
\end{tabular}

Notes: Data runs from 1983Q1-2001Q4. Interest rate spreads $\left(R_{s}\right)$ are in percentage points and annualized values. Investment $(I)$ is gross capital formulation. All series except the trade balance $(T B)$ and $R_{s}$ are logged. All series are HP filtered with a smoothing parameter of 1600 . The data source is Neumeyer and Perri (2005). a: The cross-country estimate for 1820-2004 by Tomz and Wright (2007). b: This fraction is computed by aggregating the quarterly simulated data into annual frequency.

To compute the business cycle statistics, the model is simulated 2000 times, each with 5,000 periods, and only the last 400 (100 years) observations of each simulation are used for computing the business cycle statistics to rule out any effects of initial conditions. Model series are treated equally as the data series. Simulated moments from the model are averages over the 2000 simulations, with each simulation of the same length (76 quarters) as the data sample. Specifically, when a default is detected at period $t$ in one simulation, a set of series of variables of interest from t-76 to t-1 are selected and used for computing the statistics.

In general, the model well matches the business cycle statistics of Argentina, especially consistent with the two stylized facts of emerging markets business cycles: counter-cyclicality of the trade balance and sovereign spreads, even though the model underestimates both moments. Moreover, the baseline model generates a significantly high fraction of default in "good" times (when output is above trend) of $37.9 \%$, which is very close to the estimate of Tomz and Wright (2007) of 38.5\%. Note that quantitative sovereign default models in the tradition of Eaton and Gersovitz (1981) cannot generate this high fraction of sovereign default in good times; except for few studies ${ }^{4}$, they generate defaults only in bad times, mainly because of the specification of default cost mentioned earlier.

It must be, however, noted that the fraction of defaults in good times is computed by aggregating the quarterly simulated data from the model into annual frequency, to make it comparable to the estimate of Tomz and Wright (2007), the estimate obtained using annual data. As will be discussed later in section 3.3, the time aggregation overestimates the fraction around twofold: in simulation, there are many cases, in which the model economy actually defaults in "bad" times but counts as a default in "good" times after the aggregation. However, even without the time aggregation, the model still generates a high fraction of defaults in "good" times of $16.9 \%$.

The model fails to generate a high volatility of consumption in excess of output, which is another business cycle feature unique to emerging markets economies (Aguiar and Gopinath (2007)). This is because in

\footnotetext{
${ }^{4}$ To my best knowledge, only Mendoza and Yue (2012) and Durdu et al. (2013) generate defaults in "good" times in simulation.
} 
Figure 2: Default Region
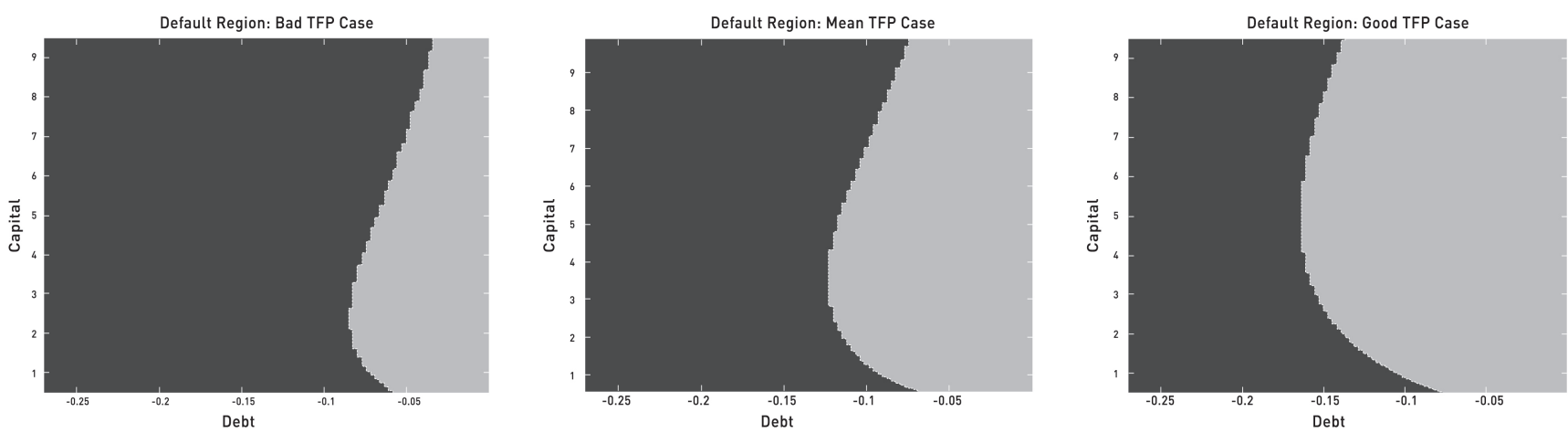

Notes: A bad and a good TFP shock denote a shock one standard deviation below and above the mean shock, respectively.

addition to non-contingent bonds, our model has another instrument for consumption smoothing: capital. In the sensitivity analysis, it is shown that our model also can generate a high volatility of consumption in excess of output with a counterfactually high capital adjustment cost, the case in which the capital stock can not be easily adjusted to smooth out consumption for the economy.

\section{Default Region}

Figure 2 shows default regions for three different levels of TFP shocks. The default region illustrates the government's default decision function $D(B, K, A)$ in $(B, K)$ space. The darkly shaded region represents combinations of current bond holdings (debt) $B$ and capital $K$, for which the government optimally chooses to default for a given level of TFP shock $A$. The lightly shaded region is the non-default region. The horizontal axis is debt and the vertical axis capital.

There are three features of the default region worth mentioning. First, other things equal, the more indebted the economy is, it is more likely to default. This is a common feature of quantitative sovereign default models in the tradition of Eaton and Gersovitz (1981). This is a consequence of the properties of value functions $\left(V^{n d}\right.$ and $V^{d}$ ) that the value of default $V^{d}$ is independent of debt, whereas the value of repayment $V^{n d}$ is decreasing in debt.

Second, the default region for a low TFP shock (left panel) contains that for a high TFP shock (right panel), implying that the economy is more likely to default for a lower productivity shock, other things equal. That is, default occurs mostly in "bad" times, which is consistent with empirical studies regarding sovereign default. This "bad" time default is the only type of default that most quantitative sovereign default models predict and has been mainly investigated in the literature.

With a low productivity shock, the economy has low output. The economy can, however, make one of two choices to increase current consumption: borrowing from foreign lenders, or defaulting on its debt. However, if terms of borrowing are not favorable, mainly due to a bad prospect of economic fundamentals associated with the persistence of a productivity shock, external borrowing does not help much to increase the economy's consumption. When income is low, which coincides with the state of a high marginal utility of consumption, the gain of the increase in current consumption from default exceeds the cost of default, so the economy chooses to default. Furthermore, today's low TFP shock predicts that tomorrow's TFP 
Figure 3: $\left(V_{d}-V_{n d}\right)$
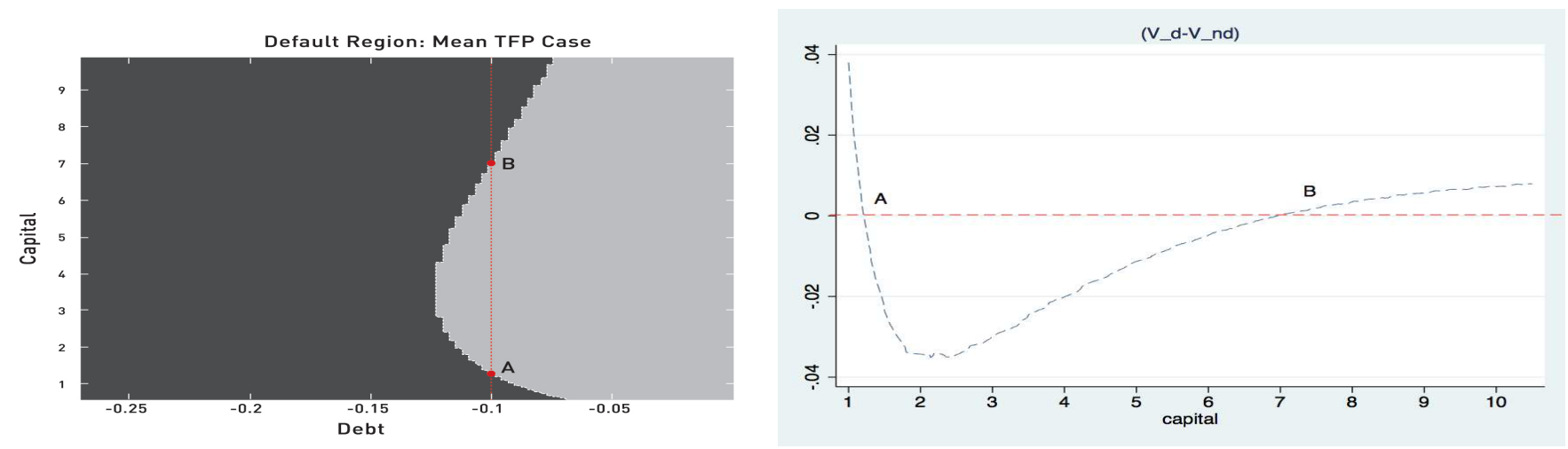

shock is also likely to low, so that the economy is not much in need to finance its in investment from external borrowing; this further lowers the value of maintaining a good relationship with foreign lenders, thereby default becoming more appealing.

Finally and interestingly, default incentives display a "U" shape along the capital axis as shown in the right panel of Figure 3, which plots the difference between the values of default and repayment $\left(V^{d}-V^{n d}\right)$ along the capital axis for the mean TFP shock and debt (the mean of the ergodic distribution). That is, default incentives are high at a very small amount of capital, but they decrease as the capital stock increases. Above a certain level of capital stock, default incentives are reversed back to increase. At a sufficiently large amount of capital (point B), the value of default starts and continues to exceed the value of repayment, thereby leading to a default decision. Note that both values of default $V^{d}$ and repayment $V^{n d}$ are increasing in capital. Hence, to see how the government's default incentives change with capital, holding other things constant, we need to know which value function increases more than the other value function with capital.

When the economy has a small stock of capital, the economy has relatively high debt to income, so that consumption conditional on repaying is less than that under default. This implies that the economy repaying the debt has a higher marginal utility of consumption than under default.; at low levels of capital, the default incentives are mainly determined by change in current utility $\left(u\left(c_{t}\right)\right)$. Consider a case in which we decrease one unit of capital at point $A$, where the government is indifferent between default and repayment. (i.e., $V^{n d}=V^{d}$ ). A decrease in income associated with the decrease in the capital stock lowers $V^{n d}$ more than $V^{d}$, thus leading to a default, because the burden of debt gets higher and the marginal utility of consumption is high at this low amount of capital. In this case, default provides consumption insurance to the economy in bad income states. This type of default is often referred to as "excusable" default, the notion proposed by Grossman and Huyck (1989).

On the other hand, at high levels of capital, conditional on the level of debt, default incentives are mainly determined by the continuation values of $V^{n d}$ and $V^{d}$, because the marginal utility of consumption is low at high income states. An increase in capital at the high level of capital stock increases $V^{d}$ more than $V^{n d}$, because the economy with a large stock of capital gets more well-prepared for autarky after default. Penalty for the defaulting country with a sufficiently large stock of capital is not high for two reasons. First, the economy does not need to borrow from foreign lenders to finance its investment for 
capital accumulation. Second, during autarky, the economy can maintain its consumption with the capital accumulated before default. That is, during autarky, capital can be used a consumption-insurance vehicle in the similar spirit of Aiyagari (1994). Moreover, after a relatively short period of autarky (on average one year under the baseline calibration), the economy can start anew with zero debt, which further works to be in favor of the value of default. Hence, at point B , an additional unit of capital increases $V^{d}$ more than $V^{n d}$, so that the economy decides to default on its debt.

Investigating envelop conditions of $V^{d}$ and $V^{n d}$ at point $\mathrm{B}$ shows this point more clearly. Ignoring the capital adjustment cost function for simplicity, the envelope conditions of $V^{d}$ and $V^{n d}$ with respect to capital gives us:

$$
V_{k}^{n d}=u_{c}\left(c_{t}^{n d}, l_{t}\right)\left\{\exp \left(A_{t}\right) f_{k}\left(K_{t}, l_{t}\right)+(1-\delta)\right\} \quad \text { and } \quad V_{k}^{d}=u_{c}\left(c_{t}^{d}, l_{t}\right)\left\{\exp \left(A_{t}\right) f_{k}\left(K_{t}, l_{t}\right)+(1-\delta)\right\}
$$

Since the optimal labor with a GHH utility function is a function of $A_{t}$ and $K_{t}$ only, comparing $V_{k}^{n d}$ and $V_{k}^{d}$ is identical to comparing $u_{c}\left(c_{t}^{n d}, \overline{l_{t}}\right)$ and $u_{c}\left(c_{t}^{d}, \overline{l_{t}}\right)$ with $\overline{l_{t}}$ fixed at the given level of capital and TFP shock. The right panel of 3 shows that at point $B, V_{k}^{n d}<V_{k}^{d}$, implying that $c_{t}^{n d}>c_{t}^{d}$. This shows that for high levels of capital, default does not work to increase consumption as in the case of the low levels of capital. Responding to a marginal increase in capital, the economy under default rather increases its investment to prepare for the autarky. The economy with a sufficiently large amount of capital wants to default, simply because of little value associated with maintaining a good relationship with foreign lenders. This type of default can be thus considered "opportunistic" or "inexcusable" compared to the default that occurs in low income states.

\section{"Excusable" Vs "Opportunistic" Default}

Except for the few studies, sovereign default models in the tradition of Eaton and Gersovitz (1981) only predict high default incentives in low income states ("excusable" default). On the other hand, another stand of sovereign default models initiated by Kehoe and Levine (1993) predict high default incentives in high income states ("opportunistic default"), even though default does not occur in equilibrium in these models. Our model, however, predicts both "excusable" and "opportunistic" motives for default, thus bridging the gap between the two strands of sovereign default models. It must be noted that the models in the line of Eaton and Gersovitz (1981) feature the non-contingent bond only framework, whereas the models in the line of Kehoe and Levine (1993) feature the framework with fully state contingent securities. Introducing capital accumulation makes the defaultable debt in our model more state contingent, bringing it closer to the framework in the line of Kehoe and Levine (1993); capital is another state variable affecting default decisions in our model.

\section{Bond Price Schedule}

The left panel of Figure 4 plots the bond price schedules $q\left(B^{\prime}, K^{\prime}, A\right)$ as a function of debt $\left(B^{\prime}\right)$ at the mean level of capital for bad, mean, and good TFP shocks. The right panel of Figure 4 plots the bond price schedules as a function of capital $\left(K^{\prime}\right)$ at the mean level of debt for the three different TFP shocks. The bond price schedule is consistent with the default region: (1) if the government borrows more today, 
Figure 4: Bond Price Schedule
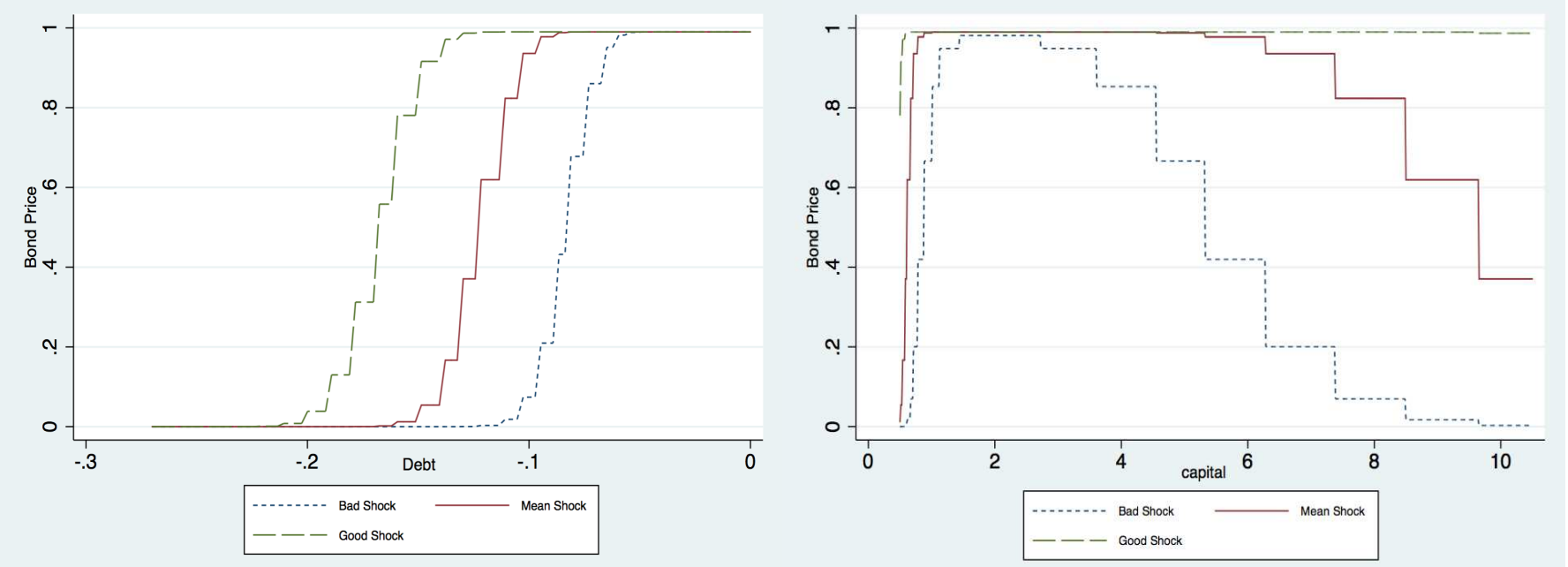

Table 3: Fraction of default in good times with annual frequency

\begin{tabular}{|c|c|c|c|c|c|}
\hline & Q1 & Q2 & Q3 & Q4 & Average \\
\hline \hline Annual frequency & $16.9 \%$ & $28.3 \%$ & $43.2 \%$ & $60.0 \%$ & $37.9 \%$ \\
\hline Quarterly frequency & \multicolumn{5}{|c|}{$16.9 \%$} \\
\hline
\end{tabular}

Note: The annual frequency at a certain quarter refers to the fraction of default in good times obtained using the aggregated data with the assumption that all the defaults in simulation are assumed to occur only at the quarter.

foreign lenders expect the government to be more likely to default next period, thereby charging a higher interest rate (i.e., a low bond price) on the debt. (2) Due to the persistent of the TFP shock process, today's good shock allows the government to borrow more at favorable terms (i.e., a high bond price). (3) If the government chooses too low or high capital $K^{\prime}$ for the next period, the investors charges a higher interest rate as the government is more likely to default for the next period at such levels of capital $K^{\prime}$.

\subsection{Time Aggregation Problem}

As discussed in the previous section about the business cycle moments, our model generates a significantly high fraction of default in "good" times of $37.9 \%$ in simulation, which is very close to the estimate of Tomz and Wright (2007) of 38.5\%. I aggregate the quarterly data from the model into annual frequency and detrend the aggregate data using the HP filter with a smoothing parameter of 400 , so as to provide a comparable estimate to that of Tomz and Wright (2007), the estimate obtained using annual data.

I find, however, the time aggregation can significantly overestimate the fraction of default in good times: when computed with the quarterly data from the model without the aggregation, the fraction sharply decreases to $16.9 \%$. For example, in one simulation, the economy defaults in the fourth quarter of a certain year when GDP is below trend, but all the GDP's for the first three quarters of the year are higher then the average. In that case, even though the economy actually defaults in bad times, the output aggregated over the whole year is slightly above trend, so that it counts as a default in good times at annual frequency. 
Figure 5: Distribution of Output and TFPs at the Time of Default
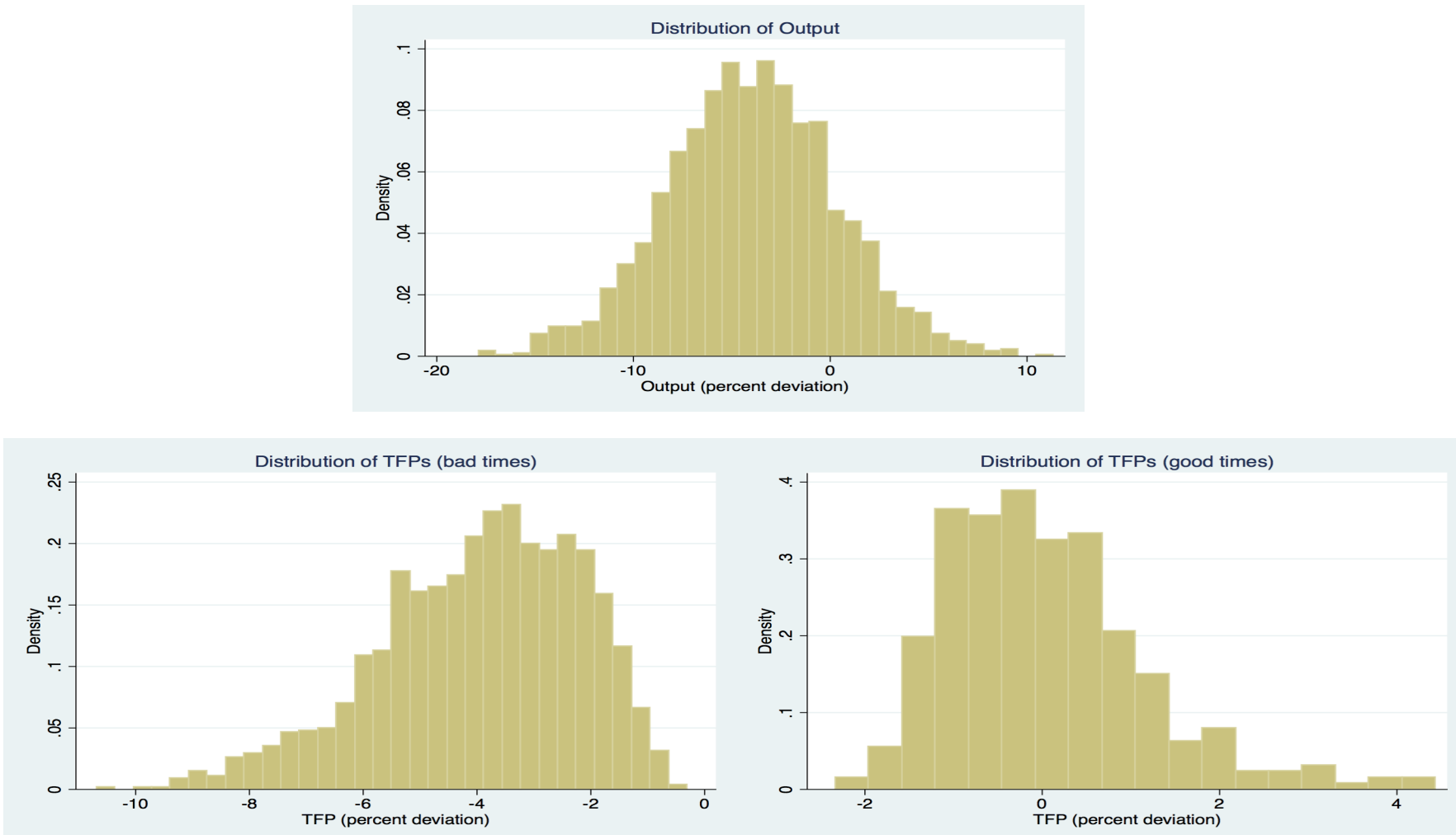

To see how the time aggregation distorts the fraction of default in good times, I conduct the following experiment. I assume that all the defaults (a total of 2000 defaults) in simulation occur only in the first quarter of the year and then aggregate the quarterly data. In this case, the fraction of defaults in good times at quarterly frequency of $16.9 \%$ exactly coincide with that at annual frequency. However, when I assume that all the defaults in simulation occurs only in the last quarter of the year, the fraction of default in good times at annual frequency becomes $60 \%$, a more than threefold increase. When assuming that all the defaults occur in the second and third quarter, the fraction at annual frequency becomes $28.3 \%$ and $43.2 \%$, respectively. This distortion is related to the persistence of the TFP shock process; if a bad time default occurs at the first quarter of a year, triggered by a significantly negative TFP shock, then TFPs in the subsequent quarters are very likely to be bad. Hence, in this case, the time aggregation does not overestimates the fraction. However, when the bad time default occurs in the fourth quarter of a year, depending on the path of TFPs preceding the default, this actual bad time default at quarterly frequency can count as either bad time or good time default after the time aggregation. This experiment suggests that the estimates by Tomz and Wright (2007) and Durdu et al. (2013) might be exaggerated, to a considerable degree, by the time aggregation, and must be interpreted with caution. Table 3 summarizes the result of the experiment.

\subsection{Distribution of Output and TFPs at the Time of Default}

The top panel of Figure (5) shows the distribution of output at the time of default (in percentage deviation from trend) for a total of 2000 defaults in simulation. The mean of output at the time of default is $-3.97 \%$ 
and left-skewed, indicating that in simulation, default occurs mostly when output is below trend. However, with the fraction of $16.9 \%$ (without time aggregation), output is above trend at the time of default. The bottom of Figure (5) plots distributions of TFP shocks, conditional on defaulting in good and bad times, respectively. For the defaults in "bad" times, all TFPs are below trend with the mean of TFP of $-3.94 \%$ and the lowest TFP is as low as $-12 \%$. On the other hand, for the defaults in good times, the mean of TFPs is just above zero (0.026\%), and the lowest TFP for the good time default in simulation is slightly below $-2 \%$. The highest TPF shock for the good time defaults is slightly above $4 \%$. That is, the default in bad times is accompanied with significantly bad TFP shocks, whereas the default in "good" times is mostly accompanied with modestly good TFP shocks.

\subsection{Macroeconomic Dynamics around Defaults}

In the previous section, we have investigated how the inclusion of capital accumulation affects sovereign's default incentives. Then, how does the inclusion of capital accumulation affect macroeconomic dynamics of the economy around default events? Moreover, how does the dynamics around defaults in good times differ from those around defaults in bad times? To answer these questions, I apply event study techniques to simulated time series data as in Mendoza and Yue (2012). The event window of Figure 6 covers 12 quarters before and after defaults, with the default normalized to date 0 . The solid line in figure 6 plots the average for each variable at each date $(\mathrm{t}-12$ to $\mathrm{t}=12)$, the average across simulated paths of all defaults (a total of 2000 defaults). The dashed line with a marker of + and $\boldsymbol{\Delta}$ denotes an average path of each variable, conditional on defaulting in bad and good times, respectively. Note that for the trade balance/output ratio and annualized spreads, the event widow ends at t-1, one period before default, because in the default

states, spreads are infinite and the trade balance is zero due to the assumption of the trade sanction as a punishment of default. 
Figure 6: Average Macro Dynamics around Default
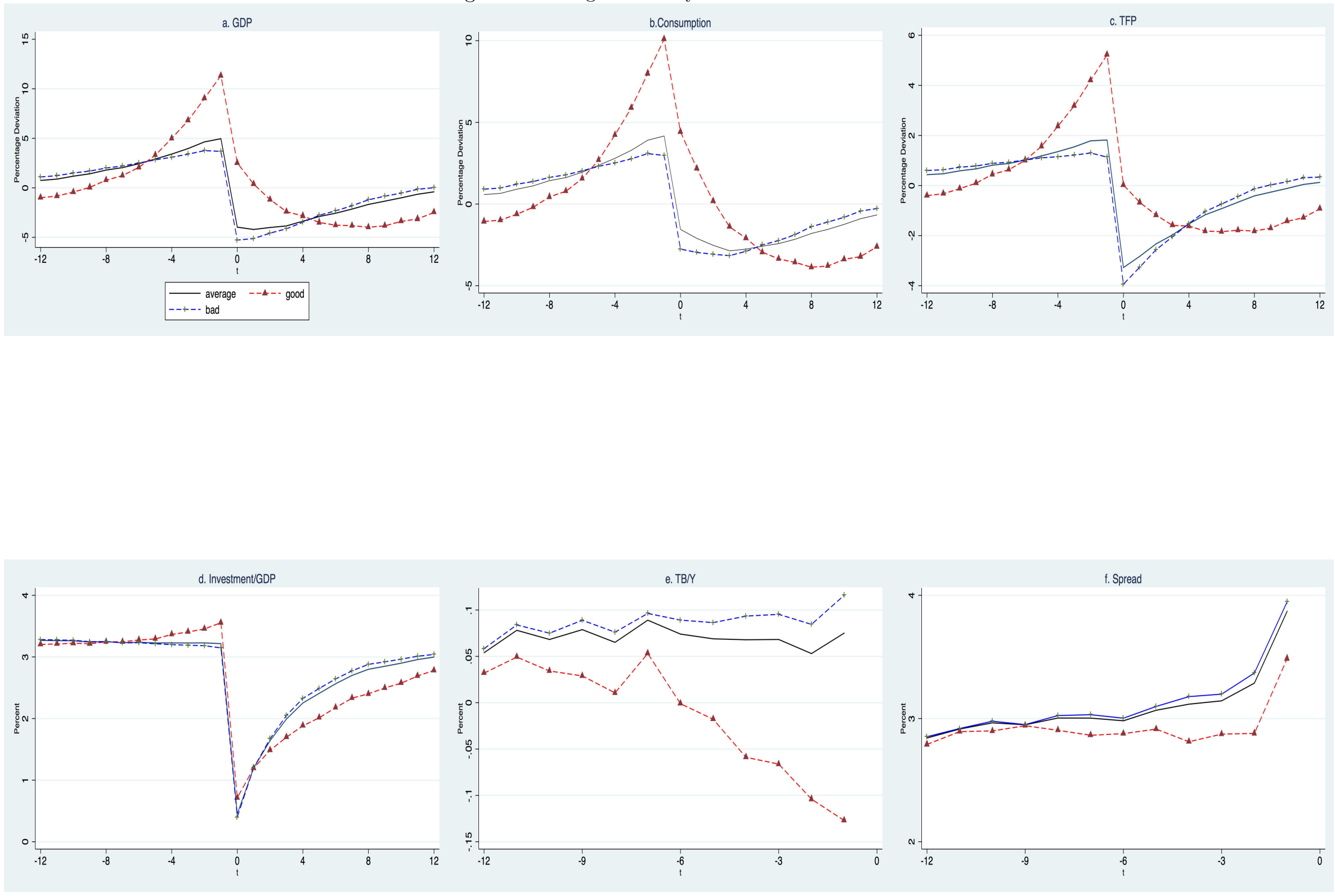

Note: GDP,Consumption, and TFP shocks are logged and HP detrended with a smoothing parameter of 1600. The unit of GDP, Consumption, and TFP shocks is percentage deviation from trend. Investment/GDP, TB/Y, and Spreads are in terms of percentage points. Spreads are annualized values. 
If we don't differentiate defaults in bad times from in good times, the model economy display, on average, the V-shaped dynamics of output, consumption, and investment as documented in Mendoza and Yue (2012): At the time of default, output collapses far below trend along with consumption and investment, but it quickly reverts back to the mean over time after the default. Moreover, the defaults are mainly triggered by significantly negative TFP shocks. The dynamics around defaults in bad times are similarly "V" shaped, because $85.1 \%$ of the total defaults occur in bad times in simulation.

On the other hand, the model economy displays different macroeconomic dynamics around defaults in good times: on average, the defaults in good times are preceded by a period of booms during which output, investment/GDP, and TFPs are rapidly increasing, but their paths suddenly reverted down to slightly above the mean at the time of default, displaying an inverted "V" shape qualitatively similar to the macroeconomic dynamics of Ecuador's 2008's default in Figure 1. Up until the two period before the defaults in good times $(\mathrm{t}=-2)$, spreads are slightly below the average value of $2.83 \%$, implying that until the two period before the default, the default deemed less likely as the TFP is much above trend at that time. ${ }^{5}$ However, at the time of default, the TFP gets unexpectedly reversed down to slightly above the mean, which predicts modest future economic fundamentals due to the persistence of the TFP shock process. The expectations about the modest TFP shocks lead to a decrease in the value of external borrowings, mainly because the economy does not have to rely on external borrowings to finance its investment, especially after having accumulated a sufficient amount of capital. Moreover, The economy with a large amount of capital can maintain its consumption during autarky with the accumulated capital, leading to an increase in the value of default. ${ }^{6}$

These differences in the macroeconomic dynamics of the two different defaults suggest that the two different defaults are linked to two different motives for default. As explained in the subsection regarding the default region, default in bad times is consistent with the notion of "excusable" default as in Grossman and Huyck (1989) in the sense that the economy defaults to insure itself against bad income shocks. On the other hand, default in good times is in line with "opportunistic" default as in Kehoe and Levine (1993) in the sense that the economy defaults when the economy does not value highly of a good relationship with the foreign lenders: facing a modestly good shock, the economy with a large stock of capital does not need to rely on foreign borrowings to finance its investment and consumption. This point can be also highlighted by the fact that default not occur when the TFP shock is very high as shown in the distribution of TFP shocks for the defaults in good times (Figure 5); with the persistent TFP shocks, the economy facing a very good TFP shock will borrow a lot from foreign lenders to finance investment, because capital is expected to be very productive. Hence, in the face of a very good TFP shock, the economy will try to maintain a good relationship rather than default.

\footnotetext{
${ }^{5}$ With the risk-neutral pricing in our model, spreads in simulation closely follow default probabilities.

${ }^{6} \mathrm{~A}$ plot of capital over GDP around default rather than investment/GDP is misleading, because default in "bad times" is associated with a sharp decrease in GDP, but capital, a stock variable, does not change immediately. Hence, The capital/GDP ratio is much higher at the time of default in "bad" times than for the default in "good times", even though the default in "good" times is preceded by a period of rapid accumulation of capital.
} 
Table 4: Sensitivity Analysis

\begin{tabular}{|c|c|c|c|c|c|c|c|c|c|}
\hline & $\sigma(y)$ & $\sigma(c) / \sigma(y)$ & $\sigma(I) / \sigma(y)$ & $\sigma\left(\frac{T B}{y}\right)$ & $\sigma\left(R_{s}\right)$ & $\rho(T B / Y, Y)$ & $\rho\left(R_{s}, Y\right)$ & Default Rate & Fraction of default in "good" times \\
\hline (1) Data & 4.22 & 1.17 & 2.95 & 1.42 & 3.87 & -0.89 & -0.63 & 2.76 & $38.5 \%$ \\
\hline (2) Baseline & 4.27 & 0.95 & 2.90 & 0.40 & 1.60 & -0.33 & -0.25 & 2.65 & $16.9 \%\left(37.9 \%^{a}\right)$ \\
\hline \multicolumn{10}{|l|}{ Depreciation Rate $(\delta=0.025)$} \\
\hline (3) $\delta=0.015$ & 4.19 & 0.94 & 3.74 & 0.29 & 4.06 & -0.30 & -0.19 & 4.6 & $16.4 \%(34.7 \%)$ \\
\hline (4) $\delta=0.04$ & 4.35 & 0.96 & 2.25 & 0.40 & 0.87 & -0.33 & -0.06 & 1.24 & $17.3 \%(38.6 \%)$ \\
\hline \multicolumn{10}{|c|}{ Capital Adjustment Cost $(\kappa=21)$} \\
\hline$(5) \kappa=11$ & 4.27 & 0.93 & 3.34 & 0.42 & 1.86 & -0.30 & -0.30 & 3.67 & $21.3 \%(44.73 \%)$ \\
\hline (6) $\kappa=51$ & 4.29 & 0.97 & 1.94 & 0.22 & 1.04 & -0.35 & -0.10 & 1.21 & $11.2 \%(24.64 \%)$ \\
\hline (7) $\kappa=100$ & 4.29 & 1.05 & 0.08 & 0.19 & 1.52 & -0.27 & -0.33 & 0.30 & $5 \%(11.23 \%)$ \\
\hline (8) Irreversible Investment & 4.28 & 0.95 & 2.75 & 0.36 & 1.52 & -0.33 & -0.27 & 2.43 & $14.7 \%(29.45 \%)$ \\
\hline
\end{tabular}

Note: a: the fraction of default in good times obtained using the data aggregated into annual frequency. 


\subsection{Role of Capital Accumulation}

The quantitative results in the previous section show that capital accumulation has crucial effects on sovereign's default incentives and macroeconomic dynamics around the defaults. To isolate the effect of capital accumulation on default incentives, a sensitivity analysis is conducted with respect to the parameters regarding capital accumulation. Table 4 presents the result of the sensitivity analysis.

Depreciation Rate of Capital $(\delta)$. During autarky when capital accumulation is costly, an increase in the depreciation rate $\delta$ leads to an increase in the cost of default. In the baseline model, $\delta$ is set at 0.025 . As the depreciation rate increases, the default rate decreases, but other than that, there is no significant change in business cycle statistics with different values of $\delta$.

Capital Adjustment Cost $(\kappa)$. As $\kappa$ increases, the cost of capital adjustment increases so that it is more costly to change the capital stock across time. The increase in $\kappa$ has two effects on default incentives. First, as it gets more costly to accumulate capital, the cost of default increases. Similar to the increase in $\delta$, a high $\kappa$ leads to a low default rate in simulations. Second, as $\kappa$ increases, the extent to which capital is used to smooth out consumption gets decreased. Hence, as $\kappa$ increases, the volatility of consumption

over output increases, and for a very high value of $\kappa$ of 100 , which corresponds to a very low $\frac{\sigma(I)}{\sigma(Y)}$ of 0.08, the volatility of consumption exceeds that of output, which brings our model closer to the sovereign default models featuring only non-contingent bonds. Moreover, the fraction of the defaults in good times is decreasing in $\kappa$ : the fraction decreases from $21.3 \%$ for $\kappa$ of 11 to $5 \%$ for $\kappa$ of 100 . This indicates that the role of capital as a consumption-smoothing instrument is crucial for the model's ability of generating defaults in good times.

Reversibility of Investment. In our baseline model, perfect reversibility of investment is assumed, meaning that capital can be converted one for one to the consumption good without any costs. Our main result is robust to the assumption of irreversibility of investment, which is consistent with Dow Jr and Olson (1992) in that the effect of irreversibility of investment is insignificant on business cycle statistics of the standard one-sector growth models. Moreover, the fraction of defaults in good times does not change much with the irreversible investment. This indicates that the capability of the economy to "eat" the capital stock during autarky does not have significant effects on opportunistic default incentives.

\section{Conclusions}

This paper introduces endogenous capital accumulation to an otherwise standard quantitative model of sovereign default in the tradition of the Eaton and Gersovitz (1981). The novel finding of this paper is that conditional on a level of debt, default incentives display a "U" shape in the stock of capital; the economy with too small or too large amounts of capital is likely to default. By introducing capital accumulation, our model predicts two different motives for default (excusable and opportunistic), thus bridging the gap between the two different strands of sovereign default models. Moreover, these two different motives for default enable the calibrated model to generate in simulation defaults in both good and bad times with the frequency close to that of the empirical finding of Tomz and Wright (2007).

The simulation results show that the model economy displays different economic dynamics around 
the two different types of defaults. For the defaults in "bad" times, the model economy displays usual "V" shape economic dynamics as has been mainly investigated by previous quantitative sovereign default models. On the other hand, default in "good" times occurs (1) after the economy has accumulated a significantly large amount of capital and (2) when the economy faces a modestly good shock, both of which reduce the value of external borrowing but increase the value of staying in autarky. Moreover, I find that the time aggregation problem can significantly overestimate the fraction of defaults in good times, suggesting that Tomz and Wright (2007) and Durdu et al. (2013) must be interpreted more carefully. 


\section{Appendix 1: Computational Algorithm}

I first discretize the bond and capital space with 200 and 700 equally spaced grid points, respectively. The TFP shock process is approximated with 31 shocks using the discretization method by Tauchen (1986).

The following computational algorithm is used to solve the model numerically.

1. Start with initial guesses for the bond price schedule $q^{0}(B, K, A)$, and the value functions $V_{0}^{D}$ and $V_{0}^{N D}$. As an initial guess for bond price schedule $q^{0}$, I use the inverse of gross interest rates, $q^{o}(B, K, A)=\frac{1}{1+r_{f}}$ for all $(B, K, A)$. For the initial guesses for $V_{0}^{D}$ and $V_{0}^{N D}, V_{0}^{D}(B, K, A)=$ $V_{0}^{N D}(B, K, A)=0$ is used for all $(B, K, A)$.

2. Given the bond price schedule, iterate value functions $\left(V^{D}, V^{N D}\right)$ until convergence with a tolerance level of $10 \mathrm{e}-5$.

3. Once the value functions converge, compute a default set and default probabilities.

4. Update the bond price schedules using default sets and default probabilities as in eq (31).

5. Iterate this procedure with the updated bond price schedules and updated value functions, until the bond price schedules converge with a tolerance level of 10e-5 (i.e., $\left|q^{i}(B, K, A)-q^{i+1}(B, K, A)\right|<$ $10 e-5$ for all coordinates.

\section{References}

Aguiar, M. and G. Gopinath (2006). Defaultable debt, interest rates and the current account. Journal of international Economics 69(1), 64-83.

Aguiar, M. and G. Gopinath (2007). Emerging market business cycles: The cycle is the trend. Journal of Political Economy 115(1), 69-102.

Aiyagari, S. R. (1994). Uninsured idiosyncratic risk and aggregate saving. The Quarterly Journal of Economics, 659-684.

Alfaro, L. and E. Hammel (2007). Capital flows and capital goods. Journal of international Economics 72(1), 128-150.

Arellano, C. (2008). Default risk and income fluctuations in emerging economies. The American Economic Review, 690-712.

Bai, Y. and J. Zhang (2012). Financial integration and international risk sharing. Journal of International Economics 86(1), 17-32.

Bulow, J. and K. Rogoff (1989). Sovereign debt: Is to forgive to forget? THE American Economic Review.

Burstein, A. T., J. C. Neves, and S. Rebelo (2004). Investment prices and exchange rates: Some basic facts. Journal of the European Economic Association 2(2-3), 302-309. 
Cuadra, G. and H. Sapriza (2008). Sovereign default, interest rates and political uncertainty in emerging markets. Journal of International Economics 76(1), 78-88.

Dow Jr, J. P. and L. J. Olson (1992). Irreversibility and the behavior of aggregate stochastic growth models. Journal of Economic Dynamics and Control 16(2), 207-223.

Durdu, C. B., R. Nunes, and H. Sapriza (2013). News and sovereign default risk in small open economies. Journal of International Economics 91(1), 1-17.

Eaton, J. and M. Gersovitz (1981). Debt with potential repudiation: Theoretical and empirical analysis. The Review of Economic Studies, 289-309.

Eaton, J. and S. Kortum (2001, June). Trade in capital goods. European Economic Review 45(7), 11951235.

Gelos, R. G., R. Sahay, and G. Sandleris (2011). Sovereign borrowing by developing countries: What determines market access? Journal of International Economics 83(2), 243-254.

Gopinath, G. and B. Neiman (2014). Trade adjustment and productivity in large crises. The American Economic Review 104(3), 793-831.

Gordon, G. and P. A. Guerron-Quintana (2013). Dynamics of Investment, Debt, and Default . Unpublished Manuscript, 1-36.

Greenwood, J., Z. Hercowitz, and G. W. Huffman (1988). Investment, capacity utilization, and the real business cycle. The American Economic Review, 402-417.

Grossman, H. and J. V. Huyck (1989). Sovereign debt as a contingent claim: Excusable default, repudiation, and reputation. American Economic Review 78(5), 1088-1097.

Hatchondo, J. C., L. Martinez, and H. Sapriza (2009). Heterogeneous borrowers in quantitative models of sovereign default*. International Economic Review 50(4), 1129-1151.

Kalesky, A. (1985). The Costs of Default. New York: Twentieth Centry Fund.

Kehoe, P. J. and F. Perri (2002). International business cycles with endogenous incomplete markets. Econometrica $70(3), 907-928$.

Kehoe, T. J. and D. K. Levine (1993). Debt-constrained asset markets. The Review of Economic Studies $60(4), 865-888$.

Kocherlakota, N. R. (1996, October). Implications of Efficient Risk Sharing without Commitment. The Review of Economic Studies 63(4), 595-609.

Lee, J.-W. (1995). Capital goods imports and long-run growth. Journal of Development Economics 48(1), 91-110.

Lucas, R. E. (1987). Models of business cycles, Volume 26. Basil Blackwell Oxford. 
Martinez, J. V. and G. Sandleris (2011). Is it punishment? sovereign defaults and the decline in trade. Journal of International Money and Finance 30(6), 909-930.

Mendoza, E. G. (1991). Real business cycles in a small open economy. The American Economic Review, $797-818$.

Mendoza, E. G. and V. Z. Yue (2012). A general equilibrium model of sovereign default and business cycles. The Quarterly Journal of Economics 127, 889-946.

Neumeyer, P. A. and F. Perri (2005). Business cycles in emerging economies: the role of interest rates. Journal of monetary Economics 52(2), 345-380.

Rebelo, S. (1991). Long-run policy analysis and long-run growth. The Journal of Political Economy 99(3), $500-521$.

Roldan, J. (2012). Default risk and economic activity: A small open economy model with sovereign debt and default. Unpublished Manuscript, Banco Central de Mexico.

Tauchen, G. (1986). Finite state markov-chain approximations to univariate and vector autoregressions. Economics letters 20(2), 177-181.

Tomz, M. and M. L. Wright (2007). Do countries default in bad times? Journal of the European Economic Association 5(2-3), 352-360.

Yue, V. Z. (2010). Sovereign default and debt renegotiation. Journal of international Economics 80(2), $176-187$. 